Martin Vlkovsky

\title{
IMPACT OF VEHICLE TYPE AND ROAD QUALITY ON CARGO SECURING
}

The article is concerned with comparison of the three transportation experiments using the two vehicle types (Tatra 810 and Tatra 815 MK IV) on two road types (higher and lower quality). From the transportation experiments, three datasets were obtained to be compared mutually and to the normatively determined values of acceleration coefficients, as well. In the article, the calculation of the probability of excess and double excess of the normatively determined limits is also included. For the purpose of the comparison, statistical tests of equality and three different parameters are employed. Statistically significant differences between the datasets are the outcome of the article, i.e. there are statistically significant differences between the vehicles and roads tested with regard to generated shocks. The results are primarily usable in the cargo securing system optimisation in road transportation and transport safety.

Keywords: transportation, cargo securing, acceleration coefficient, comparison, statistical test

\section{Introduction}

Since 2013, the amount of cargo transported via roads within the European Union (EU) has been slowly growing. The situation is similar in the Czech Republic. The year 2018 will not be an exception; in spite of the fact that there is no available data from Belgium yet, the amount of cargo transported via roads within the EU (15,114,072 thousand tons) is higher than in the previous year $(14,668,624$ thousand tons) [1]. Provided that the amount of roadtransported cargo in Belgium is analogical to the previous 5 years, i.e. approx. 300,000 tons, the increase in the amount of road-transported cargo in 2018, if compared to 2017, will be more than $5 \%$. When comparing the estimation for 2018 (15,414,072 thousand tons of transported cargo), the increase, as against 2013 (13,772,040 thousand tons), is almost $12 \%$ [1]. The number of people killed in road accidents within the EU has been rather stagnating and the data is only available for 2017 (25,257 casualties). The difference against 2013 is slightly positive; the number of casualties has decreased by more than $2.6 \%$ from the total of 25,942 [2].

The growing amount of cargo transported within the EU makes higher demands on transport infrastructure, which often cannot be maintained and fixed as required by individual EU countries. In general, the lower road quality results in greater shocks during the transport, and if the cargo securing system was not adapted, the probability of cargo loosening grows, which may, in consequence, lead to a road accident. According to European Commission Directorate-General for Energy and Transport (currently European Commission Diractorate-General - Mobility and Transport) estimations, as much as $25 \%$ of truck road accidents are caused by inappropriate or insufficient cargo securing [3]. Should the estimation (25\%) be applied to the Czech Republic in 2018, out of the total of 21,889 road accidents, $52.7 \%$ are caused by truck drivers (11,542 accidents) [4-5]. Hence, it follows from the European Commission estimation that in 2018 inappropriate cargo securing resulted in 2,886 truck road accidents, which makes for $13.2 \%$ of the total number of road accidents in the Czech Republic. For the sake of comparison, a highly discussed problem - drink driving - was the cause of 4,626 accidents in 2018, which makes for $21.1 \%$ out of the total number of road accidents, and drugs were detected in 260 road accidents, which makes for "only" $1.2 \%$ [4].

\section{Literature review}

The issue of cargo securing is dealt with in a number of reference texts. A crucial source of cargo securing principles for selected transportation types (road, railway and sea) within the EU (Czech Republic) is EN 121951:2010 standard that describes several methods of cargo securing, including the formulas for the calculation of securing forces [6]. Cargo securing by means of textile lashing straps is described in linking standard EN 121952:2003 [7]. Cargo fixation in road vehicles is also covered in two more standards EN 12640:2019 and EN 12642:2016 [8], concentrating on fixing points and car body construction [9-10]. The above-mentioned standards have been detailed in a comprehensive document "European Best Practice Guidelines on Cargo Securing for Road Transport" [3]. The best practice examples within the EU are also based on "IMO/ILO/UNECE Code of Practice for Packing of Cargo Transport Units (CTU Code)" [11]. In monographs, the issue of cargo securing is discussed rather marginally. The issue

\section{Martin Vlkovsky}

Department of Logistics, Faculty of Military Leadership, University of Defence in Brno, Czech Republic

E-mail of corresponding author: martin.vlkovsky@unob.cz 
of securing by means of the top-over lashing method is dealt with in T. Lerher's book "Cargo Securing in Road Transport Using Restraining Method with Top-over Lashing" that is complemented with case studies from the cargo securing sphere [12]. A detailed description of respective models can be found in a monograph by G. Grossmann and M. Kassmannova "Transport Safe Packaging and Cargo Securing" [13]. In reference articles, the issue of cargo securing is covered less often, as well. Cargo securing using EN 12195-1:2010, or EN 12195-2:2003 is described in articles [14-15]. The same problem is solved in other papers and focused mostly on cargo securing by fastening straps, e.g. [16-17]. An experimental approach to analyse the acceleration of vehicle was chosen in paper [18]. The issue of cargo securing a transport safety in a selected region (country) is dealt with in [19-21].

\section{Transportation experiment}

In order to obtain the data, three measurements (transportation experiments) were taken using respective vehicles on respective types of roads without cargo. For the first two transportation experiments, from which datasets formally designated as $d_{1}$ and $d_{2}$ were obtained, an off-road truck Tatra 810-V-1R0R26 $131776 \times 6.1 \mathrm{R}$ (further in the text only "Tatra 810 ") [22] was used. Tatra 810 has gross weight of $13,000 \mathrm{~kg}$ and curb weight $8,500 \mathrm{~kg}$. The front axle of the vehicle is suspended by coil springs and the rear axle by leaf springs in a rocker arm arrangement. In the third transportation experiment, from which the dataset $d_{3}$ was obtained, container carrier Tatra 815-260R81 $362558 \times 8.2$ Multilift MK IV (further in the text only "Tatra 815 MK IV") [23] was used. Tatra 815 MK IV has gross weight $32,000 \mathrm{~kg}$ and curb weight $15,500 \mathrm{~kg}$. The front axle is suspended by leaf springs and the rear axle by combination of leaf springs with compressed air bellows. The first $\left(d_{1}\right)$ and third $\left(d_{s}\right)$ experiments were carried out on a high-quality road highway [24], while the second $\left(d_{2}\right)$ experiment was carried out on a low-quality road - Class III road:

$d_{1}$ - in total measured values $n_{1}=4,059$ (1,353 per axis), highway transportation between Vyskov and Brno, average speed $v_{1}=71.84 \mathrm{~km} \cdot \mathrm{h}^{-1}$, distance $s_{1}=27.0 \mathrm{~km}$, Tatra 810 ; $d_{2}$ - in total measured values $n_{2}=1,182$ (394 per axis), Class III road transportation between Vyskov and Dedice, average speed $v_{2}=39.29 \mathrm{~km} \cdot \mathrm{h}^{-1}$, distance $s_{2}=4.3 \mathrm{~km}$, Tatra 810; $d_{3}$ - in total measured values $n_{3}=4,059$ (1,353 per axis), highway transportation between Vyskov and Brno, average speed $v_{3}=71.84 \mathrm{~km} \cdot \mathrm{h}^{-1}$, distance $s_{3}=27.0 \mathrm{~km}$, Tatra 815 MK IV.

The transport conditions of the experiments were optimal - excellent visibility, dry road, no rainfall and temperatures between $7{ }^{\circ} \mathrm{C}$ and $11^{\circ} \mathrm{C}$.

For the measurement of required data (acceleration coefficient values) in three axes $(x$ - longitudinal, $y$ transversal, and $z$ - perpendicular to the direction of the vehicle movement), a measuring device - OM-CPULTRASHOCK-5 three-axes accelerometer with a calibration certificate and a measuring range $\pm 5 g$ was used. The measuring device was placed on the cargo space steel frame in case of Tatra 810 and on the steel frame of an ISO 1C container in case of Tatra 815 MK IV, which forms part of a vehicle. During the transportation experiments, no data outside the measuring range were recorded. In the $z$-axis, the measuring device only records values over $1 g$ (acceleration of gravity) and the coordinate axis is shifted by this value $(1 g)$, which reflects even in the normatively determined limits as per EN 12195-1:2010. The normatively determined limits are formally designated with index $s$ for individual axes:

$c_{x s}$ - acceleration coefficient in the longitudinal direction ( $x$-axis) for forward/backward movements is $0.8 / 0.5$;

$c_{y s}$ - acceleration coefficient in the transverse direction ( $y$-axis), displacement/tilting is $0.5 / 0.6$;

$c_{z s}$ - vertical acceleration coefficient ( $z$-axis) is 1.0 [6].

For the purpose of the article, the "worst values" were used that can be formally written in the form of a basal vector of acceleration coefficients $\left(c_{s}\right)$, including the shift of $z$-axis by $1 g$ :

$c_{s}=(0.8,0.6,2.0)$,

for the purpose of double excess of the normatively determined limits another basal vector $\left(b_{s}\right)$ was also determined:

$b_{s}=(1.6,1.2,3.0)$

For the mutual comparison of the datasets measured and the normatively determined limits $\left(c_{s}, b_{s}\right)$, the following parameters were used: distribution $\left(\sigma_{i}\right)$, mean value arithmetic mean of absolute values $\left(\mu_{i}\right)$, probability of excess $\left(\varpi_{i}\right)$ or the double excess of normatively determined limits $\left(\rho_{i}\right)$. Index $i$ refers to the respective dataset and its value is 1,2 or 3 . For the purpose of parametric tests, the normality of experimentally obtained data $\left(d_{1}, d_{2}\right.$, $d_{3}$ ) was verified graphically using the Q-Q plots [25]. Although minor deviations from normality were detected, the respective quantiles lay approximately in one line [26]. For the mutual comparison of the datasets taking the differences between the road types and vehicle types into consideration, statistical tests of equality were employed at the level of significance $\alpha=0.05$. For each parameter, a hypothesis of equality $\left(H_{1}=H_{2}\right.$, or possibly $H_{1}=H_{3}$, or $H_{2}$ $=H_{3}$ ) was tested, and then two-tailed tests were conducted in order to find out whether the respective parameter in a dataset is, in statistical terms, significantly smaller or bigger if compared to another dataset. The comparison of the datasets was made for all the pairs $\left(d_{1}-d_{2}, d_{1}-d_{3}, d_{2}-d_{3}\right)$.

\section{Results and discussion}

For the data analysis, the above-mentioned parameters were calculated that were further used in the statistical 
Table 1 The probabilities of excess or the double excess of normatively determined limits

\begin{tabular}{|c|c|c|c|c|c|c|c|c|c|}
\hline \multirow{2}{*}{$\begin{array}{c}d_{i} \\
\text { Axis }\end{array}$} & \multicolumn{3}{|c|}{$\mathrm{d}_{1}$} & \multicolumn{3}{|c|}{$\mathrm{d}_{2}$} & \multicolumn{3}{|c|}{$\mathrm{d}_{3}$} \\
\hline & $\mathrm{x}$ & $\mathrm{y}$ & $\mathrm{z}$ & $\mathrm{x}$ & $\mathrm{y}$ & $\mathrm{z}$ & $\mathrm{x}$ & $\mathrm{y}$ & $\mathrm{z}$ \\
\hline $\mathrm{n}$ & 1.353 & 1.353 & 1.353 & 394 & 394 & 394 & 1.353 & 1.353 & 1.353 \\
\hline $\mathrm{c}_{\mathrm{s}}$ & 0.8 & 0.6 & 2.0 & 0.8 & 0.6 & 2.0 & 0.8 & 0.6 & 2.0 \\
\hline$f_{c}$ & 293 & 942 & 68 & 202 & 303 & 181 & 3 & 7 & 1 \\
\hline$\varpi$ & 0.2166 & 0.6962 & 0.0503 & 0.5127 & 0.7690 & 0.4594 & 0.0022 & 0.0052 & 0.0007 \\
\hline $\mathrm{b}_{\mathrm{s}}$ & 1.6 & 1.2 & 3.0 & 1.6 & 1.2 & 3.0 & 1.6 & 1.2 & 3.0 \\
\hline $\mathrm{f}_{\mathrm{b}}$ & 1 & 20 & 0 & 9 & 86 & 8 & 0 & 0 & 0 \\
\hline$\rho$ & 0.0007 & 0.0148 & 0.0000 & 0.0228 & 0.2183 & 0.0203 & 0.0000 & 0.0000 & 0.0000 \\
\hline
\end{tabular}

$c_{s} \quad$ normatively determined limit as per EN 12195-1:2010

$b_{s} \quad$ double limit arising from $c_{s}$

$f_{c}, f_{b}$ number of measured values excessing limit $c_{s}$, or possibly $b_{s}$

Table 2 Statistical tests of equality

\begin{tabular}{|c|c|c|c|c|c|c|c|c|c|}
\hline \multirow{3}{*}{$\begin{array}{c}\begin{array}{c}\text { Confidence } \\
\text { intervals for }\end{array} \\
\mathrm{d}_{1}<\mathrm{d}_{2}\end{array}$} & \multicolumn{9}{|c|}{ Acceleration coefficients values in individual axes } \\
\hline & \multicolumn{3}{|c|}{$\mathrm{x}$} & \multicolumn{3}{|c|}{$\mathrm{y}$} & \multicolumn{3}{|c|}{$\mathrm{z}$} \\
\hline & $\sigma_{1} / \sigma_{2}$ & $\mu_{1}-\mu_{2}$ & $\varpi_{1}-\varpi_{2}$ & $\sigma_{1} / \sigma_{2}$ & $\mu_{1}-\mu_{2}$ & $\varpi_{1}-\varpi_{2}$ & $\sigma_{1} / \sigma_{2}$ & $\mu_{1}-\mu_{2}$ & $\varpi_{1}-\varpi_{2}$ \\
\hline $\mathrm{LB}$ & 0.419 & -0.190 & -0.350 & 0.483 & -0.238 & -0.121 & 0.372 & -0.328 & -0.460 \\
\hline UB & 0.491 & -0.120 & -0.242 & 0.567 & -0.156 & -0.024 & 0.436 & -0.242 & -0.359 \\
\hline $\mathrm{PE}$ & 0.454 & -0.155 & -0.296 & 0.524 & -0.197 & -0.073 & 0.403 & -0.285 & -0.409 \\
\hline $\mathrm{d}_{1}>\mathrm{d}_{3}$ & $\sigma_{1} / \sigma_{3}$ & $\mu_{1}-\mu_{3}$ & $\varpi_{1}-\varpi_{3}$ & $\sigma_{1} / \sigma_{3}$ & $\mu_{1}-\mu_{3}$ & $\varpi_{1}-\varpi_{3}$ & $\sigma_{1} / \sigma_{3}$ & $\mu_{1}-\mu_{3}$ & $\varpi_{1}-\varpi_{3}$ \\
\hline $\mathrm{LB}$ & 1.765 & 0.492 & 0.192 & 2.676 & 0.540 & 0.666 & 1.181 & 0.468 & 0.038 \\
\hline UB & 1.963 & 0.511 & 0.236 & 2.977 & 0.563 & 0.716 & 1.313 & 0.492 & 0.061 \\
\hline $\mathrm{PE}$ & 1.861 & 0.502 & 0.214 & 2.822 & 0.552 & 0.691 & 1.245 & 0.480 & 0.050 \\
\hline $\mathrm{d}_{2}>\mathrm{d}_{3}$ & $\sigma_{2} / \sigma_{3}$ & $\mu_{2}-\mu_{3}$ & $\varpi_{2}-\varpi_{3}$ & $\sigma_{2} / \sigma_{3}$ & $\mu_{2}-\mu_{3}$ & $\varpi_{2}-\varpi_{3}$ & $\sigma_{2} / \sigma_{3}$ & $\mu_{2}-\mu_{3}$ & $\varpi_{2}-\varpi_{3}$ \\
\hline $\mathrm{LB}$ & 3.789 & 0.623 & 0.461 & 4.981 & 0.709 & 0.722 & 2.856 & 0.722 & 0.409 \\
\hline UB & 4.442 & 0.692 & 0.560 & 5.839 & 0.788 & 0.806 & 3.348 & 0.807 & 0.508 \\
\hline $\mathrm{PE}$ & 4.095 & 0.657 & 0.510 & 5.384 & 0.749 & 0.764 & 3.087 & 0.765 & 0.459 \\
\hline
\end{tabular}

PE Parameter estimation

LB Lower boundary of the $95 \%$ confidence interval

UB Upper boundary of the $95 \%$ confidence interval

tests of equality. In Table 1 , the probabilities of excess, or the double excess of the normatively determined values of acceleration coefficients, specified in EN 12195-1:2010, are presented, taking the shift of coordinate axis in the measuring device in $z$-axis by $1 g$ into consideration.

The probabilities of excess of the normatively determined limits reach high values especially with Tatra 810 off-road vehicle, or possibly Class III road. The highest values were recorded in $d_{1}$ and $d_{2}$ in the $y$-axis, which is also due to the magnitude of the normatively determined limit $\left(c_{y s}=0.6\right)$ as per EN 12195-1:2010. For the Tatra 815 MK IV vehicle the probability values are negligible, in all the three axes they were lower than $1 \%$. As far as e probabilities of the double excess of normatively determined limits are concerned, the values (refer to the experiment conducted) for Tatra the 815 MK IV and for $d_{1}$ in the $z$-axis were not available. The highest value was recorded in $d_{2}$ in the $y$-axis again.
If the extreme results of $d_{2}$ are taken as a basis, i.e. 86 double excesses of normatively determined values in the $y$-axis out of the total number of 394 measured values, the greatest risk of the cargo loosening during the transportation by Tatra 810 vehicle on Class III road is in the transversal axis. The hypothesis also works for considerably lower average transportation speed on Class III road, which was almost half the highway transportation speed.

Furthermore, statistical tests of equality at the level of significance $\alpha=0.05$ (refer to Table 2) were conducted proving statistically significant differences in monitored parameters for each pair of datasets.

From the results it clearly follows that the biggest differences are between $d_{2}$ and $d_{3}$, i.e. despite the transport speed on a lower-quality road being half the highway speed, Class III road still generates greater shocks than a highway. The magnitude of the difference is also underlined by 
Table 3 Mean values (arithmetic means) of acceleration coefficients - absolute values

\begin{tabular}{|c|c|c|c|c|c|c|}
\hline & \multicolumn{3}{|c|}{$\mathrm{d}_{1}$} & \multicolumn{3}{|c|}{$\mathrm{d}_{2}$} \\
\hline & $\mathrm{x}$ & $\mathrm{y}$ & $\mathrm{Z}$ & $\mathrm{x}$ & $\mathrm{y}$ & $\mathrm{z}$ \\
\hline Arith. mean (ABS) & 0.6873 & 0.7226 & 1.7075 & 0.8425 & 0.9196 & 1.9924 \\
\hline Median (ABS) & 0.6700 & 0.7100 & 1.6900 & 0.8150 & 0.8500 & 1.9500 \\
\hline
\end{tabular}

differences between the test vehicles as it is evident that Tatra 810 generates greater shocks than Tatra 815 MK IV under comparable transport conditions.

The results complement statistically significant differences in probabilities $\left(\varpi_{i}\right)$ of excess of the normatively determined values of acceleration coefficients in individual axes as per EN 12195-1:2010, although in the two cases the statistical difference at the level of significance $\alpha=0.05$ was close to the threshold value (refer to $d_{1}<d_{2}$ in $y$-axis and $d_{1}>d_{3}$ in $z$-axis).

It follows from the analyses conducted that in general, the Tatra 810 off-road vehicle generates greater shocks than the Tatra 815 MK IV vehicle on a high-quality road - highway. The shock values are even higher in case of Tatra 810 being operated on a low-quality road - Class III road. The mean values in $d_{1}$ and $d_{2}$ - arithmetic means of absolute values, or possibly medians of absolute values (refer to Table 3) - differ to a relatively great extent. If more precise arithmetic mean of acceleration coefficient absolute values is calculated, its value in $d_{2}$ is for $22.6 \%$ higher in the $x$-axis than in $d_{1}$, or for $27.3 \%$ in the $y$-axis, or for $16.7 \%$ in the $z$-axis. Furthermore, the results suggest that while the acceleration coefficient values can be used to determine a securing method for Tatra 815 MK IV vehicle, they are not, or to a very limited extent, applicable to Tatra 810 operation under normal conditions (see above). On a lower-quality road, the normatively determined values of acceleration coefficients are completely inapplicable for the determination of a securing method for Tatra 810 and potentially dangerous, especially in the context of possible accident occurrence (not only road-related) in consequence of the cargo shifting in the vehicle cargo space.

\section{Conclusions}

The cargo securing in road transportation is still a topical issue and a cargo is often inappropriately or insufficiently secured, which supports the above-mentioned European Committee estimations. Those insufficiencies often result from negligence, i.e. when the method of proper cargo securing is known to a responsible person (a driver, a logistics employee), but the responsible person opts for another method, usually less laborious, cheaper or less time-demanding. In the road transportation, cargo is sometimes not secured at all, as a responsible person does not expect to encounter any problems during the transport. This article, as well as author's further scientific work, mainly concentrate on another reason of inappropriate or insufficient cargo securing, which is unintentional unawareness of the cargo securing system, despite a responsible person using all the available information sources (e.g. the above-mentioned standards, or manuals, handbooks, etc.). Under normal conditions - especially on the high-quality roads - the difference between the expected magnitude of shocks and their real magnitude is usually small or there is no difference at all, i.e. it is irrelevant in relation to transport safety. The problem is encountered mainly when transporting cargos on the lower-quality roads - lower classes roads, or possibly under specific conditions, e.g. off the road or generally outside common roads, or by special vehicles (e.g. military, agricultural, Integrated Rescue System). The negative consequence may not only be a road accident as such, but an accident in general, e.g. during handling operations (in particular loading/unloading) or other activities in reloading areas, warehouses, etc. The above-mentioned flaws lead to great social losses, that can be (e.g. based on the Transport Research Centre methodology) expressed financially [27]. Hence, the results are mainly usable in the field of cargo securing optimisation and reduction of negative impacts of incorrect securing system selection.

The follow-up research shall concentrate on inclusion of further measurements, the generalisation of the results, taking into account the selected cargo transport specifics, including the transportation of hazardous materials or objects [28-29] and identification of further risks associated with the effect of shocks on cargos transported via roads [30]. In addition, more sophisticated statistical methods [31], or possibly further mathematical tools shall be employed, such as Wavelet analysis allowing the transition of data from time to frequency domain [32].

\section{Acknowledgement}

This work was supported by the Ministry of Defence of the Czech Republic under Grant ROZVOLOG: Development of Capabilities and Sustainability of Logistics Support (ROZVOLOG 2016-2020). 


\section{References}

[1] European commision - Eurostat. Goods transport by road [online]. [Viewed 2019-07-25]. Available from: https://ec.europa.eu/eurostat/databrowser/view/ttr00005/default/table?lang=en

[2] European commision - Eurostat. People killed in road accidents [online]. [Viewed 2019-07-28]. Available from: https://ec.europa.eu/eurostat/databrowser/view/sdg_11_40/default/table?lang=en

[3] European commision - Directorate-general for energy and transport. European best practice guidelines on cargo securing for road transport [online]. [Viewed 2019-07-30]. Available from: www.uirr.com/fr/component/downloads/downloads/302.html

[4] Police of the Czech Republic - Accident statistics 2018 [online]. [Viewed 2019-07-30]. Available from: https://www.policie.cz/clanek/statistika-nehodovosti-900835.aspx?q=Y2hudW09Mg\%3d\%3d

[5] Ministry of Transport of the Czech Republic - Transport yearbook 2018 [online]. [Viewed 2019-07-22]. Available from: https://www.sydos.cz/cs/rocenka-2018/rocenka/htm_cz/cz18_621000.html

[6] EN 12195-1. Load restraining on road vehicles - safety - part 1: calculation of securing forces. Prague: Czech Office for Standards, Metrology and Testing, 2010.

[7] EN 12195-2. Load restraint assemblies on road vehicles - safety - part 2: web lashing made from man-made fibres. Prague: Czech Office for Standards, Metrology and Testing, 2003.

[8] JAGELCAK, J., VRABEL, J., NIEUWESTEEG, M. Draft for revision of the standards EN 12640 and EN 12641 regarding the securing of cargo on road means of transport. LOGI - Scientific Journal on Transport and Logistics [online]. 2017, 8(2), p. 41-46. ISSN 2336-3037. Available from: https://doi.org/10.1515/logi-2017-0015

[9] EN 12640 (F draft). Securing of cargo on road vehicles - lashing points on commercial vehicles for goods transportation - minimum requirements and testing. Prague: Czech Office for Standards, Metrology and Testing, 2019.

[10] EN 12642. Securing of cargo on road vehicles - body structure of comercial vehicles - minimum requirements. Prague: Czech Office for Standards, Metrology and Testing, 2016.

[11] United nations economic commission for Europe. IMO/ILO/UNECE code of practice for packing of cargo transport units (CTU Code) [online]. [Viewed 2019-07-25]. Available from: https://www.unece.org/fileadmin/DAM/trans/doc/2014/wp24/CTU_Code_January_2014.pdf

[12] LERHER, T. Cargo securing in road transport using restraining method with top-over lashing. New York: Nova, 2015. ISBN 978-1-61122-002-5.

[13] GROSSMANN, G., KASSMAN, M. Transport safe packaging and cargo securing. 3. ed. Renningen: Expert Verlag, 2018. ISBN 978-3-8169-3334-2.

[14] JAGELCAK, J. Equation of the standard EN 12195-1 stipulates unreasonable demands for cargo securing. Communications - Scientific Letters of the University of Zilina [online]. 2007, 9(4), p. 30-33. ISSN 1335-4205, eISSN 2585-7878. Available from: http://komunikacie.uniza.sk/index.php/communications/article/view/1151

[15] JAGELCAK, J., GNAP, J. Different measures for load securing create barriers in international road freight transport. Archives of Transport Systems Telematics. 2011, 4(2), p. 10-17. ISSN 1899-8208.

[16] JAGELCAK, J., SANIGA, J. Analysis of elongation of lashing straps on movements of cargo secured by a top-over lashing at sliding in longitudinal direction. Perner's Contacts. 2013, 8(2), p. 53-62. ISSN 1801-674X.

[17] LININS, A., BERJOZA, D. Experimental investigation in acceleration of vehicle. 9th International Scientific Conference on Engineering for Rural Development Location : proceedings. 2010. ISSN 1691-5976, p. 149-153.

[18] ZAMECNIK, J., JAGELCAK, J., SOKJER-PETERSSEN, S., HVOJNIK, T., LIPKA, M. Influence of a lashing strap winding in tensioning ratchet on the results of the strength tests and cyclic loading tests according to the standard EN 121952. Communications - Scientific Letters of the University of Zilina [online]. 2017, 19(2), p. 10-17. ISSN 1335-4205, eISSN 2585-7878. Available from: http://komunikacie.uniza.sk/index.php/communications/article/view/175

[19] ZONG, C.-Q., ZHANG, H.-W., HUANG, CH.-Z., DONG, J.-S. Research on the influence of cargo securing force with typical road alignments and vehicle working conditions. 4th International Conference on Transportation Information and Safety (ICTIS): proceedings [online]. IEEE, 2017. ISBN 9781538604380, p. 27-32. Available from: https://doi.org/ 10.1109/ICTIS.2017.8047737

[20] BANNER, S. Restraining order. Commercial Motor. 2005, 201(5133), p. 54-59. ISSN 0010-3063.

[21] CIESLA, M., HAT-GARNCARZ, G. The problem of proper cargo securing in road transport - case study. Transport Problems. 2013, 8(4), p. 27-33. ISSN 1896-0596, eISSN 2300-861X.

[22] VLKOVSKY, M., VESELIK, P. Cargo securing - comparison of different quality roads. Acta Universitatis Agriculturae et Silviculturae Mendelianae Brunensis [online]. 2019, 67(4), p. 1015-1023. ISSN 1211-8516, eISSN $2464-8310$. Available from: https://doi.org/10.11118/actaun201967041015

[23] KOLMAS, V., KOHOUTEK, J., VYMETAL, J. Catalog of automotive and tracked vehicles used in the ACR. Prague: Ministry of Defence of the Czech Republic - AVIS, 2007. ISBN 978-80-7278-382-3. 
[24] VLKOVSKY, M., BINAR, T., SVARC, J., NEMEC, P., BUCSUHAZY, K. Impact of shocks on cargo securing during the road transport. 4th World Multidisciplinary Civil Engineering, Architecture, Urban Planning Symposium: proceedings. Vol. 471. Prague: IOP Conference Series - Materials Science and Engineering. 2019. ISSN 1757-8981.

[25] JOHNSON, R. A., WICHERN, D. W. Applied multivariate statistical analysis. Englewood Cliffs: Prentice-Hall International, 1992. ISBN 0130418072.

[26] VLKOVSKY, M., VLACHOVA, H. Securing cargo during transport on roads of different quality. 5th International Conference on Vehicle Technology and Intelligent Transport Systems 2019: proceedings. Heraklion: SCITEPRESS, 2019. ISBN 978-989758374-2, p. 25-32.

[27] VLKOVSKY, M., VESELIK, P., GRZESICA, D. Cargo securing and its economic consequences. 22nd International Scientific Conference Part I - Transport Means 2018 : proceedings. Kaunas: Kaunas University of Technology, 2018. ISSN 1822-296X, p. 129-135.

[28] VLKOVSKY, M., RAK, L. Cargo securing in selected vehicles and transport of explosives. Permer's Contacts [online]. 2017, 12(3), p. 101-110. ISSN 1801-674X. Available from: http://pernerscontacts.upce.cz/PC_482017.pdf

[29] DVORAK, Z., FUCHS, P., NOVAK, J., SOUSEK, R. Individual and social risk during transportation of dangerous substances. Communications - Scientific Letters of the University of Zilina [online]. 2011, 13(2), 92-98. ISSN 1335-4205, eISSN 2585-7878. Available from: http://komunikacie.uniza.sk/index.php/communications/article/ view/828

[30] DVORAK, Z., RAZDIK, J., SOUSEK, R., SVENTEKOVA, E. Multi-agent system for decreasing of risk in road transport. 14th International Scientific Conference - Transport Means 2010: proceedings. Kaunas: Kaunas University of Technology, 2010. ISSN 1822-296X, p. 100-103.

[31] VESELIK, P., DVORSKA, A., MICHALEK, J. Half a year of co-located gaseous elemental mercury measurements: investigation of temporal changes in measurement differences. Fresenius Environmental Bulletin. 2017, 26(5), p. 3128-3137. ISSN 1018-4619.

[32] VLKOVSKY, M., KOZIOL, P., GRZESICA, D. Wavelet based analysis of truck vibrations during off-road transportation. 14th International Conference on Vibration Engineering and Technology of Machinery : proceedings. Lisabon: MATEC Web of Conferences, 2018. ISSN 2261-236X. 